\title{
The Association Between Polypharmacy and Physical Function in Older Adults: a Systematic Review
}

\author{
Andreas Katsimpris, $M D^{7}$, Jacob Linseisen, $\mathrm{MD}^{1,2}$, Christa Meisinger, $M D, M P H^{1,2}$, and \\ Konstantinos Volaklis ${ }^{1,3,4}$
}

'Ludwig-Maximilians-Universität München, UNIKA-T Augsburg, Augsburg, Germany; ${ }^{2}$ Helmholtz Zentrum München, Institute of Epidemiology, Neuherberg, Germany; ${ }^{3}$ Department of Prevention and Sports Medicine, Technische Universität München, Munich, Germany; ${ }^{4} 7 \mathrm{FIT}, \mathrm{Cardiac}$ Rehabilitation Center, Augsburg, Germany.

BACKGROUND: Reduced physical function and polypharmacy (PPha) are two highly prevalent negative effects of aging, which are expected to increase more, since demographic aging is expected to grow rapidly within the next decades. Previous research suggests that polypharmacy (PPha) is a predictor of poor physical function and vice versa in older adults and therefore we conducted a systematic review of the literature to summarize and critically analyze the relationship between physical function and PPha and vice versa in older adults, in order to provide recent scientific evidence.

METHODS: We searched MEDLINE and Embase from their inception to 19th October 2018 for Englishlanguage observational studies or trials assessing the effect of PPha on physical function and vice versa in older adults. Two investigators independently extracted study data and assessed the quality of the studies, after having screened the available studies from the literature search. Any disagreement was resolved by consensus.

RESULTS: Eighteen observational studies met the inclusion criteria. Eight studies assessed the impact of physical function on PPha and ten studies assessed the impact of PPha on physical function. Regarding the studies with PPha measurements as the outcome, all of them, except for one, found that better physical function is associated with lower risk of PPha. Likewise, all the studies with physical function measurements as the outcome, except for one, suggested that PPha is associated with lower physical function.

DISCUSSION: Evidence examining the effect of PPha on physical function and vice versa in older adults suggests a strong bidirectional association between these two factors and clinicians should be aware of this strong relationship. The limitations of our study include the high variability in PPha definitions and physical function measures, and the treatment of PPha and physical function as constant instead of time-varying variables in the studies' analyses.

Andreas Katsimpris is the first author.

Electronic supplementary material The online version of this article (https://doi.org/10.1007/s11606-019-05106-3) contains supplementary material, which is available to authorized users.

Received February 20, 2019

Revised May 3, 2019

Accepted May 20, 2019

Published online June 25, 2019
KEY WORDS: polypharmacy; physical fitness; older adults.

J Gen Intern Med 34(9):1865-73

DOI: $10.1007 / \mathrm{s} 11606-019-05106-3$

(c) Society of General Internal Medicine 2019

\section{INTRODUCTION}

Demographic aging is expected to grow rapidly within the next decades ${ }^{1}$ and as a consequence, the proportion of older adults (aged 65 or older) who are at increased risk for adverse health outcomes, including hospitalization, multimorbidity and mortality, is expected to increase (percentage change of older adults from $11.7 \%$ in 2013 to $21.1 \%$ in 2050).

Reduced physical function and polypharmacy (PPha) are two common negative effects of aging and both are highly prevalent in this population. The prevalence of PPha, usually defined as receiving five or more medications, ${ }^{2}$ ranges between 27 and 59\% in primary care patients and between 46 and $84 \%$ in hospitalized patients, ${ }^{3}$ while the involuntary loss of skeletal muscle mass, strength, and function leads to sarcopenia and frailty, ${ }^{4}$ which are two common pathological features characterizing the majority of older adults.

PPha and reduced physical function frequently co-occur, increasing the risk of adverse clinical outcomes especially among those who suffer from multiple chronic diseases. Prior studies in the elderly found that exposure to PPha has been associated with impaired physical function and functional decline, increased risk of falls, and mortality. ${ }^{5}$ On the other side, a growing body of data also suggested that low physical function and low levels of physical activity are inversely and independently associated with PPha risk even after adjusting for potential confounders. Thus, it seems that a strong bidirectional association between these two factors exists and as far as we know, no systematic review has been done on this topic.

Therefore, we summarized and critically analyzed the existed literature on the relationship between physical function and PPha and vice versa in older adults in order to provide recent scientific evidence. 


\section{METHODS}

\section{Data Sources and Searches}

The review has adopted the Preferred Reporting Items for Systematic Reviews and Meta-Analyses (PRISMA) guidelines. ${ }^{6}$ The literature search was composed to answer the question, "Is there an association between PPha and physical function among individuals older than 65 years of age?" The electronic databases of published biomedical literature were searched via the databases MEDLINE and Embase (OvidSP 1946 to October Week 2 2018). The keywords inserted in the search query of OvidSP were related to the research question and the relevant inclusion and exclusion criteria of our review. Every term was searched as a MeSH term, if available and also as a free text word in order to also retrieve "In Process" and "publisher-supplied citations" as they are not indexed with MeSH. Apart from using terms derived from the hierarchically organized terminology for indexing and cataloging, we also used synonyms of these keywords, especially for PPha and physical function, because both these keywords do not have strict definitions. Search of the reference lists of all the studies, which met the inclusion criteria, was also conducted in order to retrieve articles relevant to the research question of the review. The exact combination of keywords that was put in the search query of the OvidSP databases is shown in Table 1.

\section{Study Selection}

All studies measuring medication use either as a continuous or as a categorical variable consisting of different groups according to the number of these medications were included. This is justified since there is no general agreement about the definition of PPha in the scientific literature. Only studies investigating populations covering an age range that also included individuals older than 65 years were selected. Given the broad range of determinants and instruments to measure physical

Table 1 Search Strategy 19/10/2018

\begin{tabular}{lll}
\hline \hline Step & Searches & Results \\
\hline 1 & exp physical fitness/ & 34,725 \\
2 & exp activities of daily living/ & 78,258 \\
3 & exp muscle strength/ & 53,962 \\
4 & exp gait/ & 46,697 \\
5 & exp health status/ & 207,825 \\
6 & exp mobility limitation/ & 10,060 \\
7 & (physical fitness or activit* of daily living & 202,461 \\
& or muscle strength or gait or health status \\
& or mobility limitation).tw. & \\
8 & (((physical or function*) adj (performance \\
& or capacity or ability or disability)) or & 91,882 \\
9 & physical function*).tw. & \\
10 & 1 or 2 or 3 or 4 or 5 or 6 or 7 or 8 & 504,237 \\
& exp polypharmacy/ or (polymedication or & 17,035 \\
11 & polypharmacy).tw. & 24,026 \\
& ((multip* or concomitant* or concurrent* \\
& or suboptim* or excess*) adj (medicin* & \\
& or medicat* or prescrib* or prescription* & \\
12 & or drug*).tw. & 39,796 \\
13 & 10 or 11 & 1958 \\
14 & 9and 12 & 1895 \\
\hline
\end{tabular}

function, there was no limitation regarding the instruments utilized by the studies to assess the physical function of the participants. Additionally, only such studies were included that applied adjustment in their statistical analysis for at least demographical data and comorbidity or specific diseases like diabetes, congestive heart failure, and ischemic heart disease, since they are strong confounders of the association between physical function and PPha. The date range of the literature search was from the inception of the databases until 19th October 2018; there was no restriction regarding the type, the geographical region of the study, and the context of living of individuals (e.g., community or institutions); and only English-language studies were included.

We excluded studies, in which the study population comprised of individuals with a specific disease, such as cancer, as our research question was not referring to a specific disease group of older people. Studies, which were only examining the association of Drug Burden Index, specific drugs or classes of drugs, and components of suboptimal prescribing except PPha, were excluded, because the main interest of our review was to investigate the association between the number of drugs used and physical function and not the one between specific drugs and physical function. Finally, observational studies other than cross-sectional, case-control, or cohort studies were not included in our search strategy.

\section{Data Extraction and Quality Assessment}

Two investigators (A. K., K. V.) independently screened the titles and abstracts of articles yielded from the literature search. Then, they assessed the full-text publications of potentially relevant articles for complying or not with the inclusion criteria. Disagreements were resolved by consensus. For every study that met the inclusion criteria, the same two researchers extracted the main elements, characterizing the studies. These include the main author, the country and the year, in which the study was published, the design, the follow-up period, the sample size and the population characteristics of the study, the measures of PPha and physical function which were used, and finally the main results of the study.

The quality of the studies was assessed by same two investigators through the Newcastle-Ottawa Scale (NOS) for cohort and case-control studies and a modified version of NOS for cross-sectional studies, which was described in a previous study. ${ }^{7}$ Any discrepancies were resolved by consensus. The maximum score was nine for cohort and case-control studies and ten for cross-sectional studies. Studies with scores of six or more were considered of moderate or good quality.

\section{Data Synthesis and Analysis}

We created evidence tables with studies' main results and characteristics in order to summarize the current literature. Since we considered studies with poor quality (NOS score of less than six) to lack of validity, we summarized only studies of moderate and good quality. Moreover, we grouped studies 
into two groups: a first one with PPha measures as the outcome and a second one with physical function measures as the outcome. Finally, given the high heterogeneity of the studies in terms of population and methodological characteristics, definition of PPha, and measurement of physical function, we decided to summarize studies qualitatively and that metaanalysis was not recommended.

\section{RESULTS}

\section{Identification of Studies}

In total, 1853 nonduplicated studies were yielded from the medical database search (Fig. 1). After the initial screening of titles, 204 studies were selected for reading the abstract; after abstract reading, 19 were chosen for full-text reading. Only 14 met the inclusion criteria and in addition, 4 studies identified from reference lists were included, resulting to a total number of 18 articles.

\section{Studies Characteristics}

All the studies were observational and specifically, nine were prospective cohort studies, ${ }^{8-16}$ eight were crosssectional studies, ${ }^{17-24}$ and one was a case-control study. ${ }^{25}$ Six studies were conducted in the USA $;^{10-12,17-19}$ two each in Germany, ${ }^{21,}{ }^{24}$ Japan, ${ }^{22,}{ }^{23}$ Italy, ${ }^{13}, 15$ and the $\mathrm{UK} ;{ }^{16,25}$ and one study each in Australia, ${ }^{20}$ Taiwan, ${ }^{8}$ and Finland. ${ }^{9}$ One study $^{14}$ was a multicenter cohort study, which was conducted in 50 European (seven countries) and seven Israeli facilities. The study size ranged between 294 and 29,544 individuals and for most of the studies, the sample consisted of community-dwelling individuals who were surveyed, interviewed, or assessed while living at their home. In two studies, ${ }^{13}, 15$ the population of interest was older patients admitted to the geriatric and internal medicine acute wards of specific hospitals and in two studies, ${ }^{12,14}$ the study sample comprised of institutionalized individuals. The lower limit of age of the population in most of the studies was 65 years except for two studies, ${ }^{9,21}$ which included people older than 70 years old, one study with a lower limit of age being 50 years, ${ }^{25}$ and two studies without age restriction. ${ }^{14,18}$ For most of the studies, investigating the association between PPha and physical function was defined as a primary objective $\mathrm{e}^{8-19,21,22,24,25}$ and in two studies, ${ }^{20,23}$ examining this association was a secondary objective.

\section{Measures of Medications}

Despite the fact that the most commonly reported definition of PPha across studies $8,11,12,14,16,19,21,23$ was the numerical definition of five or more medications being used on a regular basis, there were also a variety of other definitions, using cutoffs of four, six, eight, nine, ten, and eleven medications to differentiate between PPha and non-PPha groups. Three studies ${ }^{10,17,20}$ used a continuous measure of medications and one ${ }^{25}$ categorized the number of medications into 4 groups. Major, hyper-PPha or excessive PPha groups were defined in four studies, with the cut-offs being nine and ten medications, respectively in each study ${ }^{8,9}, 14,15$ and two studies ${ }^{13,19}$ used also an alternate cut-off to define PPha, in order to further confirm their results. Regarding the type of medications, most of the studies measured the number of prescriptions and OTCs as medications. ${ }^{9-13,17-19,21,22}$ The data associated with measurement of medication use in individuals were acquired mostly through face-to-face or telephone interviews, medical assessments, questionnaires, or postal surveys.

\section{Measures of Physical Function}

The most common measurement of physical function was derived from the use of basic ADL and instrumental ADL scales. In total, 9 studies ${ }^{8-10,12,14,15,17,18,20-22}$ used scales of ADLs-Barthel Index, ${ }^{26}$ Lawton-Brody IADL Scale, ${ }^{8,9,} 12$ Katz Index of ADLs, ${ }^{8,} 15,{ }^{20}$ Minimum Data Set ADL Hierarchy Scale,${ }^{14}$ OARS Scale of ADLs ${ }^{10}$ - all of them resulting in a numerical total score, which evaluated ADL. Four of these studies, ${ }^{9}, 17,18,21$ did not report the scale of ADLs they used. Only one study ${ }^{10}$ used the continuous outcome for statistical analysis. The rest transformed the outcome into a categorical variable with two or more groups. The groups were either formed depending on the score or depending on the existence of at least one dependency problem at ADLs. Four studies used objective measures of physical fitness, like walking speed, ${ }^{13}, 16,19$ grip strength, ${ }^{16,}{ }^{24}$ walking while talking speed, ${ }^{19}$ chair rise speed, ${ }^{16}$ standing balance time, ${ }^{16}$ and change in lower extremity physical function, ${ }^{11}$ as continuous measurements. The rest of the studies used the physical functioning score of SF- $36^{23}$ and the 3-year change in the physical component summary of SF-12 questionnaire as continuous variables. In the statistical analyses, grip strength was categorized into simple ${ }^{13}$ or gender-specific tertiles ${ }^{24}$ or was used as numerical variable, ${ }^{13,16}$ walking speed was categorized into tertiles ${ }^{13}$ or used as numerical variable, ${ }^{16,19}$ the 3 -year change in the physical component summary of SF-12 questionnaire was dichotomized in two groups of negative or positive change, ${ }^{25}$ walking while talking speed was used as numerical outcome, and the physical functioning score of SF-36 was categorized into three groups of high, mid, and low function.

\section{Quality of the Studies}

All studies included in the review had scores higher than 6 , and thus considered as of moderate or good quality (online appendix Table 1). The median quality score for cohort and case-control studies was 7 with a range of 6-9 and for cross-sectional studies, it was 8 with a range of $7-$ 9. All the included studies adjusted for the strong potential confounders age, sex, and comorbidity or specific diseases. 

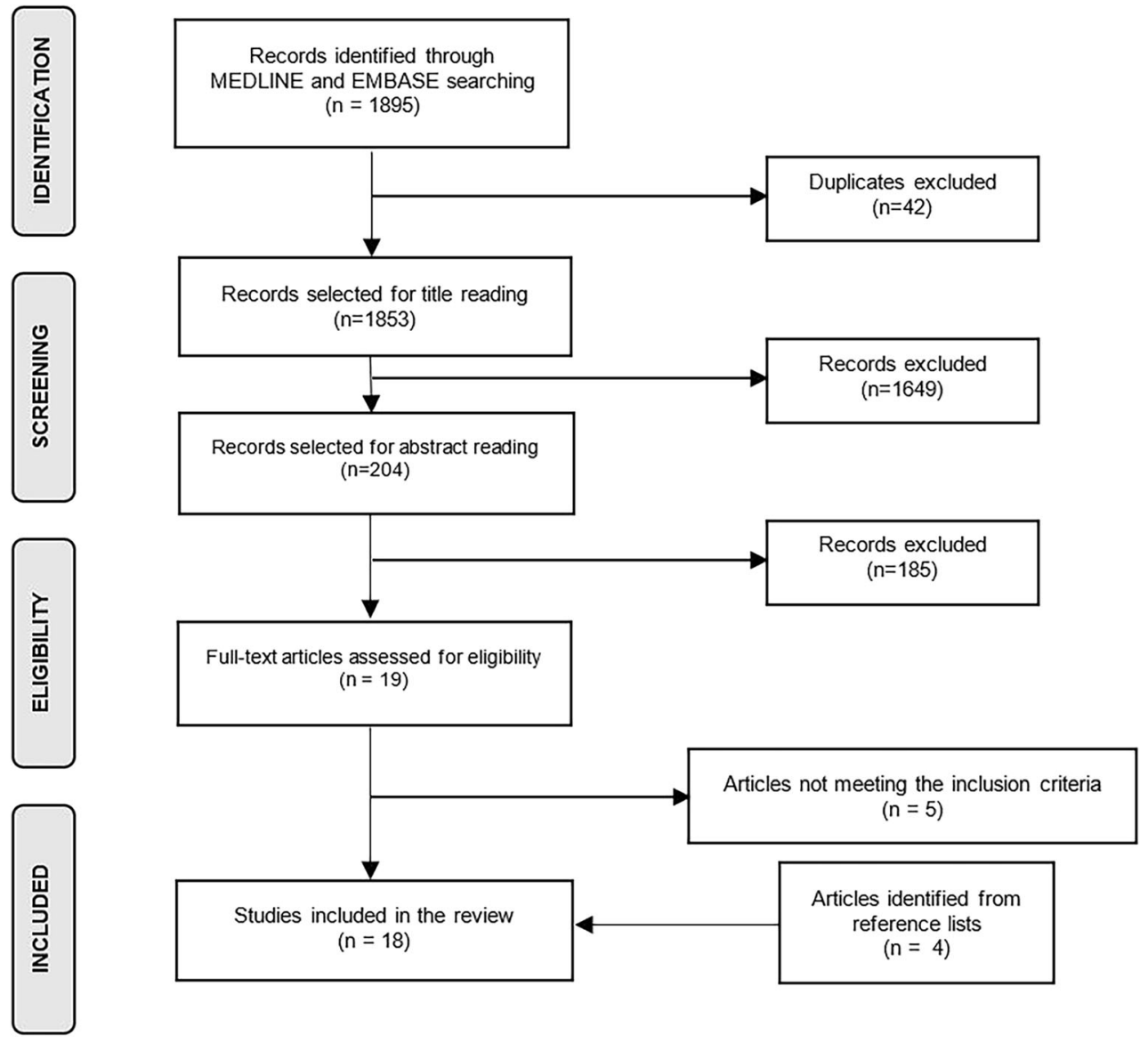

Fig. 1 Flowchart of the selection strategy of the studies.

\section{PPha as the Outcome Variable}

Eight studies ${ }^{8}, 13,17,18,21-24$ used PPha measurements as the outcome and all of them, except for one, ${ }^{24}$ found that better physical function is associated with lower risk of PPha (Table 2). Six of them were of cross-sectional nature ${ }^{17,18,21-}$

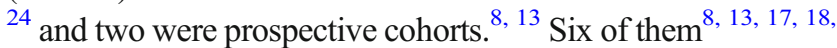
21, 22, 24 showed that older adults in lower physical function groups were more likely to have PPha or excessive PPha compared to people in the higher physical function groups. Tsuji-Hayashi et al. ${ }^{23}$ also showed that the odds of having PPha gets higher with every one-unit increase in the physical function score of SF-36 survey. This was not the case in the study of Volaklis et al., ${ }^{24}$ where although they found a significant association between physical activity and PPha, the association between grip strength and PPha was not significant.

\section{Physical Function as the Outcome Variable}

Ten studies incorporated the physical function variable, as the outcome in their statistical analysis ${ }^{9-12,14-16,19,20,25}$ and all of them, except for one, ${ }^{14}$ found that PPha is associated with lower physical function (Table 3). Seven of them were prospective cohort studies, ${ }^{9-12,}{ }^{14-16}$ two of them were crosssectional studies, ${ }^{19,20}$ and one was a case-control study. ${ }^{25}$ Seven of them $911,12,15,16,19,25$ showed that older adults in the PPha or excessive PPha group had lower physical function compared to people in the non-PPha group. Magaziner et al. ${ }^{10}$ and Gnjidic et al. ${ }^{20}$ also showed that physical function of older adults gets worse with every medication added to their medical therapy. On the contrast, Vetrano et al. ${ }^{14}$ reported that PPha is not associated with functional decline over 1 year, in older nursing home residents.

\section{DISCUSSION}

To our best knowledge, this is the first systematic review to investigate the relationship between PPha and physical function and according to our results a strong bidirectional association between these two factors exists. Specifically, PPha negatively influences the majority of physical function outcomes, while on the other hand, the lower the physical function or the physical activity level of older adults the higher the likelihood of them to be on PPha.

\section{Effects of PPha on Physical Function}

Several conceptual schemes about the process of functional impairment and disability have been proposed, with the disablement process being one of the most multifaceted. ${ }^{27}$ According to that scheme, one of the essential extra-individual 
Table 2 Characteristics and Results From Included Studies with Polypharmacy as the Outcome

\begin{tabular}{|c|c|c|c|c|}
\hline $\begin{array}{l}\text { Author, } \\
\text { country, } \\
\text { year }\end{array}$ & $\begin{array}{l}\text { Study design, } \\
\text { follow-up, } \\
\text { sample size }\end{array}$ & Population & $\begin{array}{l}\text { Measures of PPha } \\
\text { (medications) }\end{array}$ & $\begin{array}{l}\text { Measures of } \\
\text { physical function }\end{array}$ \\
\hline $\begin{array}{l}\text { Tsuji-Hayashi } \\
\text { et al., Japan, } \\
1999^{23}\end{array}$ & $\begin{array}{c}\text { Cross-sectional, } \\
n=491\end{array}$ & $\begin{array}{l}\text { Nationally representative } \\
\text { sample of Japanese } \\
\text { population, age } \geq 65\end{array}$ & PPha $\geq 5$ (only Rx) & $\begin{array}{l}\text { Physical function score } \\
\text { of SF-36 survey } \\
\text { ranging from } 0 \text { to } 100\end{array}$ \\
\hline $\begin{array}{l}\text { Kuzuya et al., } \\
\text { Japan, } 2006^{22}\end{array}$ & $\begin{array}{l}\text { Cross-sectional, } \\
n=1875\end{array}$ & $\begin{array}{l}\text { Community-dwelling } \\
\text { people eligible for } \\
\text { long-term care } \\
\text { insurance } \\
\text { in Nagoya City, Japan, } \\
\text { age } \geq 65\end{array}$ & $\begin{array}{l}\text { PPha } \geq 6 \text { (OTCs } \\
\text { and } \mathrm{Rx})\end{array}$ & $\begin{array}{l}\text { Summary score of the } \\
\text { rating of seven ADL } \\
\text { divided in three categories } \\
\text { low }(\leq 11) \text {, mid }{ }^{12-17} \text { vs } \\
\text { high function }(\geq 18)\end{array}$ \\
\hline $\begin{array}{l}\text { Junius-Walker } \\
\text { et al., Germany, } \\
2006^{21}\end{array}$ & $\begin{array}{l}\text { Cross-sectional, } \\
n=466\end{array}$ & $\begin{array}{l}\text { Systematically selected } \\
\text { patients from } 67 \\
\text { randomly selected } \\
\text { practices in Leipzig and } \\
\text { Hannover, age } \geq 70\end{array}$ & $\begin{array}{l}\text { PPha } \geq 5 \text { (OTCs } \\
\text { and } \mathrm{Rx})\end{array}$ & $\begin{array}{l}\text { Dependency problems vs } \\
\text { independency in IADLs }\end{array}$ \\
\hline $\begin{array}{l}\text { Chan et al., } \\
\text { Taiwan, } 2009^{8}\end{array}$ & $\begin{array}{l}\text { Prospective } \\
\text { cohort, 1 year, } \\
n=11,788\end{array}$ & $\begin{array}{l}\text { Nationally representative } \\
\text { sample of disabled } \\
\text { Taiwanese, age } \geq 65\end{array}$ & $\begin{array}{l}\text { Major } P P h a \geq 10, \\
\text { PPha } \geq 5, \\
\text { Persistent } P P h a \\
\geq 5 \text { for } \geq 181 \\
\text { days (only } \mathrm{Rx} \text { ) }\end{array}$ & $\begin{array}{l}3 \text { groups: IADL } \\
\text { impairments only, ADL } \\
\text { impairments vs } \\
\text { independent }\end{array}$ \\
\hline
\end{tabular}

Dwyer et al USA, $2010^{18}$ Cross-sectional,
$n=13,403$

Nationally representative sample of US nursing home residents, no restriction in age

Crentsil et al., USA, $2010^{17}$

Cross-sectional, $n=803$

Sganga et al.,

Prospective cohort, length of stay in hospital, $n=1123$

\section{Population-based, random} sample of communitydwelling disabled woman, age $\geq 65$

Patients admitted to the geriatric and internal medicine wards of seven Italian hospitals in Italy, age $\geq 65$
PPha $\geq 9$ (Rx and OTCs)

Continuous (Rx and OTCs)

PPha $\geq 10$ and PPha $\geq 8$ (alternative cut-off, Rx, and OTCs)
Number of ADLs $\leq 4$ vs all 5 requiring assistance by nursing home staff based on face-to-face interview

Self-reported IADL in difficulty in shopping vs no-difficulty

Tertiles (intermediate, good, unable vs poor continuous scale of walking speed (WS) and of grip strength (GS)

PPha $\geq 4$ (only Rx)

Gender-specific tertiles of grip strength measured in kilograms $(\mathrm{kg})$ using a handheld dynamometer performers) and

NOS Results describing the risk of PPha use by measures of physical function $(95 \% \mathrm{CI})$

8/10 OR of PPha: $0.980(0.968-$ $0.992)$ per 1 unit increase in physical function

9/10 OR of PPha: 1.35 (1.03-1.79) mid vs high function group, 1.38 (0.99-1.89) low vs high function group

7/10 OR of PPha: 1.91 (1.03-3.56) dependency problems vs independency in IADLs

$8 / 9$

OR of major PPha: 1.48 (1.27-1.72) ADL impairments vs independent, 1.35 (1.11-1.64) IADL impairments only vs independent

OR of PPha: $1.66(1.40-1.96)$ ADL impairments vs independent, 1.26 (1.01-1.57) IADL impairments only vs independent

OR of Persistent PPha: 2.11

(1.75-2.54) ADL impairments vs independent, 1.76 (1.41-2.19) IADL impairments only vs independent

9/10 OR of PPha: $0.68(0.62-0.74)$ all 5 vs $\leq 4$ ADLs requiring assistance

7/10 Ratio of total: (1) medications 1.07 (0.98-1.18), (2) prescriptions 1.20 (1.06-1.35), and (3) OTCs $0.85(0.72-0.99)$ between difficulty in shopping vs no-difficulty

6/9 OR of PPha: walking speed, $0.58(0.35-0.96)$ good vs poor performers, 0.77 (0.60-0.98) for $1 \mathrm{SD}$ increment.

OR of PPha: grip strength, $0.55(0.36-0.84)$ good vs poor performers, 0.71 $(0.56-0.90)$ for $1 \mathrm{SD}$ increment (only the first cut-off results are presented) $8 / 10$ OR of PPha: NS

$$
\begin{array}{lcl}
\begin{array}{l}
\text { Volaklis et al., } \\
\text { Germany, }
\end{array} & \begin{array}{c}
\text { Cross-sectional, } \\
2017^{24}
\end{array} & \begin{array}{l}
\text { Random sample from } \\
\text { KORA-Age study } \\
\text { (follow-up study of } 4
\end{array} \\
& & \text { surveys in Augsburg } \\
& \text { population), } 65 \leq \text { age } \leq \\
& 94
\end{array}
$$

NOS Newcastle-Ottawa Scale, CI confidence intervals, PPha polypharmacy, OR odds ratio, SF-36 36-Item Short Form Survey, OTCs over-the-counter drugs, Rx prescriptions, ADL activities of daily living, CHF congestive heart failure, CHD coronary heart disease, DM diabetes mellitus, HT hypertension, IADL instrumental activities of daily living, COPD chronic obstructive pulmonary disease, OA osteoarthritis, MMSE Mini Mental State Examination, PPSS physical performance summary score, PAD peripheral arterial disease, MI myocardial infarction, IHD ischemic heart disease, HF heart failure, SD standard deviation, KORA Cooperative Health Research in the Region Augsburg, CRP C-reactive protein, NS not significant 
Table 3 Characteristics and Results from included Studies with Physical Function as the Outcome

\begin{tabular}{|c|c|c|c|c|c|c|}
\hline $\begin{array}{l}\text { Author, } \\
\text { country, } \\
\text { year }\end{array}$ & $\begin{array}{l}\text { Study design, } \\
\text { follow-up, } \\
\text { sample size }\end{array}$ & Population & Measures of PPha & $\begin{array}{l}\text { Measures of physical } \\
\text { function }\end{array}$ & NOS & $\begin{array}{l}\text { Results describing the } \\
\text { level of physical function } \\
\text { by PPha groups }(95 \% \mathrm{CI})\end{array}$ \\
\hline $\begin{array}{l}\text { Magaziner } \\
\text { et al., USA, } \\
1989^{10}\end{array}$ & $\begin{array}{l}\text { Prospective cohort, } \\
1 \text { year, } n=609\end{array}$ & $\begin{array}{l}\text { Population-based, } \\
\text { random sample } \\
\text { from community- } \\
\text { dwelling women } \\
\text { residing in } 20 \\
\text { contiguous Zip } \\
\text { Code areas in } \\
\text { Baltimore, } \\
\text { Maryland, } \\
\text { age } \geq 65\end{array}$ & $\begin{array}{l}\text { Continuous } \\
\text { (OTCs and Rx) }\end{array}$ & $\begin{array}{l}\text { Score for IADLs and } \\
\text { PADLs } \\
\text { (0: independent individual, } \\
\text { 1: needs help, } 2 \text { : unable to } \\
\text { do any activity) }\end{array}$ & $7 / 9$ & $\begin{array}{l}\text { Change in IADL score } \\
\text { (standardized coefficients) } \\
\text { per 1-unit increase of } \\
\text { prescriptions: } 0.12 \text { (N of Rx } \\
\text { prescriptions, } p<0.001 \text { ) } \\
\text { Change in PADL score per } \\
\text { 1-unit increase of } \\
\text { prescriptions: } \\
-0.10 \text { (N of prescriptions), } \\
0.26\left(\mathrm{~N}^{2} \text { of prescriptions, }\right. \\
p<0.001 \text { ), } \\
\text { Changes in PADL per } 1 \text {-unit } \\
\text { increase of OTCs: }-0.14 \\
\text { (N of OTCs) and } 0.27:\left(\mathrm{N}^{2}\right. \\
\text { of OTCs, } p<0.001 \text { ) }\end{array}$ \\
\hline $\begin{array}{l}\text { Pugh et al., } \\
\text { USA, } 2007^{11}\end{array}$ & $\begin{array}{l}\text { Prospective cohort, } \\
7 \text { years, } n=1682\end{array}$ & $\begin{array}{l}\text { Regional probability } \\
\text { sample of community- } \\
\text { dwelling Mexican- } \\
\text { Americans, age } \geq 65\end{array}$ & $\begin{array}{l}\text { PPha } \geq 5 \text { (OTCs } \\
\text { and } \mathrm{Rx})\end{array}$ & Rate of change in LEFL & $7 / 9$ & $\begin{array}{l}\text { Mean difference in rate of } \\
\text { change in LEFL: } 0.014 \\
(p=0.004) \text { PPha vs } \\
\text { non-PPha group }\end{array}$ \\
\hline $\begin{array}{l}\text { Jyrkkä et al., } \\
\text { Finland, } \\
2011^{9}\end{array}$ & $\begin{array}{l}\text { Prospective cohort, } \\
3 \text { years, } n=294\end{array}$ & $\begin{array}{l}\text { Population-based, } \\
\text { random sample of } \\
\text { people from Kuopio, } \\
\text { Finland, age } \geq 75\end{array}$ & $\begin{array}{l}\text { PPha 6-9, } \\
\text { Excessive PPha } \\
>9 \text { (OTCs and } \\
\text { Rx) }\end{array}$ & $\begin{array}{l}\text { Self-reported IADL } \\
\text { (significant difficulty } 0-6 \\
\text { vs high functionality } 6-8 \\
\text { score) }\end{array}$ & $7 / 9$ & $\begin{array}{l}\text { OR of high functionality: } \\
-0.53(-0.81 \text { to }-0.26) \\
\text { Excessive PPha vs } \\
\text { non-PPha, }-0.29(-0.47 \\
\text { to }-0.10) \text { PPha vs non-PPha }\end{array}$ \\
\hline $\begin{array}{l}\text { Kadam et al., } \\
\text { UK, } 2011^{25}\end{array}$ & $\begin{array}{l}\text { Case-control, } \\
n=4506\end{array}$ & $\begin{array}{l}\text { Population-based, } \\
\text { postal survey at } \\
\text { baseline and at } 3 \text {-year } \\
\text { follow-up in } 6 \text { general } \\
\text { practice populations of } \\
\text { individuals, age } \geq 50 \\
\text { with } 5 \text {-year linkage } \\
\text { to their drug } \\
\text { prescription data }\end{array}$ & $\begin{array}{l}\text { Category } 4 ; \geq 12, \\
\text { category } 3 ; 8-11, \\
\text { category } 2 ; 5-7 \\
\text { vs category } 1 ; \\
1-4 \text { (only Rx) }\end{array}$ & $\begin{array}{l}\text { Dichotomized change of } \\
\text { 3-year follow-up score of } \\
\text { physical and psychological } \\
\text { component summary of } \\
\text { SF-12 questionnaire (4 } \\
\text { groups: controls had better } \\
\text { physical and psychological } \\
\text { health) }\end{array}$ & $7 / 9$ & $\begin{array}{l}\text { OR of worse physical health: } \\
1.64(1.2-2.3) \text { category } 4, \\
1.42(1.1-1.9) \text { category } 3 \text {, } \\
1.24(0.97-1.6) \text { category } 2 \\
\text { vs category } 1 \\
\text { OR of worse physical and } \\
\text { psychological health: } 2.91 \\
(2.0-4.2) \text { category } 4,2.25 \\
(1.7-3.1) \text { category } 3,1.55 \\
\text { (1.2-2.1) category } 2 \text { vs } \\
\text { category } 1\end{array}$ \\
\hline $\begin{array}{l}\text { Gnjidic et al., } \\
\text { Australia, } \\
2012^{20}\end{array}$ & $\begin{array}{l}\text { Cross-sectional, } \\
n=1705\end{array}$ & $\begin{array}{l}\text { Random sample of } \\
\text { community-dwelling } \\
\text { men, age } \geq 70\end{array}$ & $\begin{array}{r}\text { Continuous } \\
\text { (only Rx) }\end{array}$ & $\begin{array}{l}\text { Self-reported disability in } \\
\text { at least one ADL vs } \\
\text { no-disability }\end{array}$ & $8 / 10$ & $\begin{array}{l}\text { OR of disability in ADLs: } \\
1.080(1.000-1.115) \text { for } \\
1 \text {-unit increase in number } \\
\text { of medications }\end{array}$ \\
\hline $\begin{array}{l}\text { Rosso et al., } \\
\text { USA, } 2013^{12}\end{array}$ & $\begin{array}{l}\text { Prospective cohort, } \\
3 \text { years, } n= \\
29,544\end{array}$ & $\begin{array}{l}\text { Community-based, } \\
\text { recruitment of } \\
\text { community-dwelling } \\
\text { free of disability in } \\
\text { ADLs women, age } \geq \\
65\end{array}$ & $\begin{array}{l}\text { PPha } \geq 5 \text { (OTCs } \\
\text { and prescriptions) }\end{array}$ & $\begin{array}{l}\text { Incident disability in at } \\
\text { least one from four ADLs }\end{array}$ & $8 / 9$ & $\begin{array}{l}\text { RR of incident disability: } \\
1.95(1.54-2.46) \geq 5 \text { vs } \\
0-5 \text { medications }\end{array}$ \\
\hline $\begin{array}{l}\text { George et al., } \\
\text { USA, } 2017^{19}\end{array}$ & $\begin{array}{l}\text { Cross-sectional, } \\
n=482\end{array}$ & $\begin{array}{l}\text { Community-dwelling, } \\
\text { English-speaking, and } \\
\text { ambulatory } \\
\text { individuals, } \\
\text { age } \geq 65\end{array}$ & $\begin{array}{l}\text { PPha } \geq 5 \text { and } \\
\text { PPha } \geq 8 \text { (alternate } \\
\text { cut-off, OTCs, } \\
\text { and } \mathrm{Rx} \text { ) }\end{array}$ & $\begin{array}{l}\text { Velocity measured during } \\
\text { steady state walking speed } \\
\text { (WS) and walking while } \\
\text { talking speed (WWT) } \\
\text { (gait performance) }\end{array}$ & $8 / 10$ & $\begin{array}{l}\text { Mean difference of WS: } \\
-4.6 \mathrm{~cm} / \mathrm{s}(-9.0 \text { to } \\
-0.16) \text { PPha }(\geq 5) \text { vs } \\
0-4 \text { medications, }-9.4 \\
\mathrm{~cm} / \mathrm{s}(-16 \text { to }-2.8) \\
\text { PPha }(\geq) 8 \text { vs } 0-7 \\
\text { medications } \\
\text { Mean difference of WWT: } \\
\text { NS, PPha } \geq 5 \text { vs } 0-4 \\
\text { medications, }-7.9 \mathrm{~cm} / \mathrm{s} \\
(-15.3 \text { to }-0.47) \text { PPha } \\
\geq 8, \text { vs } 0-7 \text { medications }\end{array}$ \\
\hline $\begin{array}{l}\text { Vetrano et al., } \\
\text { Europe and } \\
\text { Israel, } 2018^{14}\end{array}$ & $\begin{array}{l}\text { Prospective cohort, } \\
1 \text { year, } n=3234\end{array}$ & $\begin{array}{l}\text { Nursing home residents } \\
\text { from } 57 \text { facilities, no } \\
\text { restriction in age }\end{array}$ & $\begin{array}{l}\text { PPha } 5-9, \text { excessive } \\
\text { PPha } \geq 10 \text { (only Rx) }\end{array}$ & $\begin{array}{l}\text { ADL hierarchy scale } \\
\text { ranging from } 0 \text { (no } \\
\text { impairment) to } 6 \text { (total } \\
\text { dependence) }\end{array}$ & $8 / 9$ & NS \\
\hline $\begin{array}{l}\text { Fabbietti et al., } \\
\text { Italy, } 2018^{15}\end{array}$ & $\begin{array}{l}\text { Prospective cohort, } \\
3 \text { months, } n=733\end{array}$ & $\begin{array}{l}\text { Patients admitted to the } \\
\text { geriatric and internal } \\
\text { medicine wards of } \\
\text { seven Italian hospitals } \\
\text { in Italy age } \geq 65\end{array}$ & $\begin{array}{l}\text { Hyper-PPha > } \\
10 \text { vs (only Rx) }\end{array}$ & $\begin{array}{l}\text { Functional decline defined } \\
\text { as loss of independency } \\
\text { in at least one ADL after } \\
3 \text { months from hospital } \\
\text { discharge }\end{array}$ & $6 / 9$ & $\begin{array}{l}\text { OR of functional decline: } \\
2.2(1.11-4.37) \\
\text { hyper-PPha vs } 0-9 \\
\text { medications }\end{array}$ \\
\hline $\begin{array}{l}\text { Rawle et al., } \\
\text { UK, } 2018^{16}\end{array}$ & & $\begin{array}{l}\text { Population sample from } \\
\text { the NSHD, age }=69\end{array}$ & $\begin{array}{l}\text { PPha } \geq 5 \\
\text { (only Rx) }\end{array}$ & & $7 / 9$ & $\begin{array}{l}\text { PPha vs non-PPha mean } \\
\text { differences in: }\end{array}$ \\
\hline
\end{tabular}


Table 3. (continued)

\begin{tabular}{|c|c|c|c|c|c|c|}
\hline $\begin{array}{l}\text { Author, } \\
\text { country, } \\
\text { year }\end{array}$ & $\begin{array}{l}\text { Study design, } \\
\text { follow-up, } \\
\text { sample size }\end{array}$ & Population & Measures of PPha & $\begin{array}{l}\text { Measures of physical } \\
\text { function }\end{array}$ & NOS & $\begin{array}{l}\text { Results describing the } \\
\text { level of physical function } \\
\text { by PPha groups (95\% CI) }\end{array}$ \\
\hline & $\begin{array}{l}\text { Prospective cohort, } \\
5 \text { to } 9 \text { years, } \\
n=2122\end{array}$ & $\begin{array}{l}\text { at the end of the } \\
\text { follow-up }\end{array}$ & & $\begin{array}{l}\text { Chair rise speed, standing } \\
\text { balance time, walking } \\
\text { speed, and grip strength }\end{array}$ & & $\begin{array}{l}\text { (1) Chair rise speed } \\
\text { (stands/min): }-2.4 \\
(-3.6 \text { to }-1.2) \\
\text { (2)Walking speed }(\mathrm{m} / \mathrm{s}) \text { : } \\
-0.1(-0.1-0.0) \\
\text { (3) Standing balance } \\
\text { time (log seconds): } \\
-0.1(-0.2-0.0) \\
\text { (4) Grip strength }(\mathrm{kg}) \text { : } \\
-1.9(-2.9 \text { to }-0.9)\end{array}$ \\
\hline
\end{tabular}

NOS Newcastle-Ottawa Scale, CI confidence intervals, OTCS over-the-counter drugs, Rx prescriptions, PADL physical activities of daily living, OARS Older Americans Resources and Services, $N$ number, NS not significant, $p$ p value, PPha polypharmacy, LEFL lower extremity functional limitation, MMSE Mini Mental State Examination, CESD Center for Epidemiological Studies Depression, IADL instrumental activities of daily living, FCI Functional Comorbidity Index, SF-12 12-Item Short Form Survey, OR odds ratio, ADL activities of daily living, RR risk ratio, BMI body mass index, HT hypertension, CHF congestive heart failure, DM diabetes mellitus, MI myocardial infarction, IHD ischemic heart disease, COPD chronic obstructive pulmonary disease, GDS Geriatric Depression Score, NSHD Medical Research Council National Survey of Health and Development

factors, which controls the natural way of a disease to functional impairment is medications. In that sense, drug use does not only imply protective effects but also negative ones for the physical function status, usually derived from drug-drug and drug-disease interactions, side effects, and/or inappropriate dosages of medications. For example, statin usage can induce severe side effects such myalgia or rhabdomyolysis, ${ }^{28}$ betablockers modifies local muscular metabolic properties and impairs endurance exercise, ${ }^{29}$ while several other types of drugs including corticosteroids and chemotherapy drugs are associated to muscle weakness and wasting. ${ }^{26,} 30,31$ The accumulation of concurrent diseases in older persons increases the complexity of creating an optimized prescription of medications and requires their number and potential benefit to be balanced with their adverse outcomes. As a result, the probability of functional impairment of individuals gets higher as the number of medications they use increases.

Apart from the complexity of balancing positive and adverse effects of medications, also the pharmacodynamics of specific drugs may act as mediators of the adverse impact of multiple drug use on physical function. Specific classes of medications, like drugs which depress the central nervous system, have been more correlated with decreased physical and mental functioning in older people than other classes and hence the Drug Burden Index (DBI) was introduced. ${ }^{32}$ DBI quantifies the drug burden of sedative and anticholinergic drug use of individuals and their impact on functioning. Therefore, even if the association between DBI and PPha has not been investigated yet, it is possible for DBI to describe a mediator function of the adverse effects of PPha on physical function, since with the use of an increased number of medications, the probability of using sedative and anticholinergic drugs increases.

\section{Effects of Physical Function on PPha}

During the last decades low physical function has been recognized as a risk factor for various chronic diseases, ${ }^{33-38}$ exercise training and many drugs have been shown to have comparable effectiveness regarding their mortality reduction in several chronic diseases, ${ }^{39-41}$ whereas it has also been established that among individuals with cardiovascular and metabolic diseases systematic exercise reduces the medications needed for disease treatment. ${ }^{42-44}$

Moreover, it is known that one of the main determinants of physical function is the clinical condition of individuals, which mainly consists of the cognitive and neuromuscular function, orthopedic problems and symptoms, like fatigue, pain, and shortness of breath of the individual. ${ }^{45}$ Impairment in physical function of individuals, which occur due to attenuation of their clinical condition, usually follows a proper medication treatment, with the intention to restore, as far as possible, their health state back to normal. This justifies why the concurrent diseases or clinical status of an individual is the main determinant for drug needed and even more for PPha. ${ }^{46}$

Based on this scientific background, it seems that physical function has the potential to influence PPha risk indirectly, by changing the risk of chronic diseases and multimorbidity, and directly, by acting as a predictor of the clinical condition of individuals.

\section{Clinical Implications}

Both physical function and PPha are modifiable factors, which are susceptible to interventions through healthcare providers. Quality of pharmacotherapy of older people has the potential to be improved; lowering the number of subjects on PPha in the population ${ }^{47}$ and optimization on drug prescribing ${ }^{48}$ are ways to achieve that. One well-established approach for improving the physical function of older adults is commitment in physical activity. ${ }^{49}$ Several studies ${ }^{50,51}$ have revealed that moderate and even small amount of physical activity can confer protection from functional limitations and adverse health outcomes in older adults. Therefore, physicians and other health care professionals should encourage patients to 
enhance their level of physical activity in order to counteract the age-related decline in several physiologic functions, protecting by this way against chronic diseases and thus against PPha. Moreover, the implementation of physical function improvement interventions in community settings is costeffective $^{52}$ and can affect a large number of older adults. In conjunction with amelioration of the quality of pharmacotherapy, harmful loops of dysfunction can be discontinued and adverse health outcomes can be prevented among older adults.

\section{Strengths and Limitations}

Multimorbidity is associated with both deterioration of physical function and increased number of medications; ${ }^{53-56}$ thus, it is one of the strongest confounders regarding the associations between the exposures and outcomes we tried to address. The fact that all the selected studies included an index of multimorbidity or specific chronic diseases as covariates in their statistical analysis means that they resulted in associations, which are closer to the real ones, and that is a particular strength of the study. Furthermore, the fact that all studies included several other confounders in their final adjustment models strengthens our results even more.

Taking into account that a consensus for the definition of PPha does not exist in the literature, ${ }^{2}$ a diverse range of different cut-offs in the total number of medications exists. Given the fact that, the optimal cut-off point of total medications in relation with physical function is $5.5,{ }^{20}$ most of the studies could have generated stronger associations, if they had used five or more medications as the definition of PPha. Still though, most studies, found statistically significant results, meaning that the association between PPha and physical function remains strong, even after the attenuating effect of not choosing the optimal cut-off point.

Another limitation refers to the different instruments, which were used among the studies, for measuring the physical function outcomes. Taking into consideration the variety of elements that constitute physical function, it is obvious that one measure that comprises all areas does not exist. Apart from this, only four studies used objective measures of physical function and all the studies used a one-item measurement, which covers one specific domain of physical function and is not as robust as a multidimensional instrument. In addition, some of the studies used self-administered questionnaires to measure physical function of the individuals, which could have introduced self-reporting bias. ${ }^{57}$

All studies used one or both of the exposure and outcome variables as constant variables over time. Of course, the number of medications being used by an individual fluctuates over time, e.g., due to an imperfect adherence to prescribed medication or the occurrence of new diseases. The situation is similar with respect to physical function, which has the potential to change over time in individuals. Finally, despite the inclusion of multiple synonyms of PPha and physical function in our search query, the heterogeneity of definitions and nomenclature of these concepts could possibly have affected the results of our search strategy.

\section{Conclusion}

In summary, this systematic review provides clear evidence of a bidirectional association between PPha and physical function. As the population gets older, both the burden of PPha and impairments in physical function are increasing. As both factors are potentially modifiable, health care providers could take the chance and develop effective measures to improve the health situation of older individuals by improving both conditions. A quality check of combined drug use and physical function measurements in older patients could be implemented in clinical practice, for improvement of the clinical evaluation of older patients. However, a causal relationship cannot be proven based on the current literature, but possible physiological mechanisms support our findings. Therefore, future studies, especially randomized clinical trials, applying objective measures of physical function and PPha, are needed, to establish the causal relationships between these two factors.

Corresponding Author: Andreas Katsimpris, MD; LudwigMaximilians-Universität München UNIKA-T Augsburg, Augsburg, Germany (e-mail: Andreas.Katsimpris@campus.lmu.de).

\section{Compliance with Ethical Standards:}

Conflict of Interest: The authors declare that they do not have a conflict of interest.

\section{REFERENCES}

1. United Nations DoEaSA, Population, Division. World population ageing 2013. 2015.

2. Masnoon N, Shakib S, Kalisch-Ellett L, Caughey GE. What is polypharmacy? A systematic review of definitions. BMC Geriatr 2017;17(1):230.

3. Elmståhl S, Linder H. Polypharmacy and inappropriate drug use among older people - a systematic review. Healthy Aging Clin Care Elder 2013;5(3642-HACCE-Polypharmacy-and-Inappropriate-Drug-Useamong-Older-People-a-Systema.pdf):1-8.

4. Morley JE. Frailty and sarcopenia in elderly. Wien Klin Wochenschr 2016;128(Suppl 7):439-45.

5. Fried TR, O'Leary J, Towle V, Goldstein MK, Trentalange M, Martin DK. Health outcomes associated with polypharmacy in community-dwelling older adults: a systematic review. J Am Geriatr Soc 2014;62(12):2261-72.

6. Moher D, Liberati A, Tetzlaff J, Altman DG. Preferred reporting items for systematic reviews and meta-analyses: the PRISMA statement. Ann Intern Med 2009; 151(4):264-9, w64.

7. Modesti PA, Reboldi G, Cappuccio FP, Agyemang C, Remuzzi G, Rapi S, et al. Panethnic differences in blood pressure in Europe: a systematic review and meta-analysis. PLoS One 2016;11(1):e0147601.

8. Chan DC, Hao YT, Wu SC. Polypharmacy among disabled Taiwanese elderly: a longitudinal observational study. Drugs Aging 2009;26(4):345-54.

9. Jyrkka J, Enlund H, Lavikainen $\mathbf{P}$, Sulkava $\mathbf{R}$, Hartikainen $\mathbf{S}$. Association of polypharmacy with nutritional status, functional ability and cognitive capacity over a three-year period in an elderly population. Pharmacoepidemiol Drug Saf 2011;20(5):514-22.

10. Magaziner J, Cadigan DA, Fedder DO, Hebel JR. Medication use and functional decline among community-dwelling older women. J Aging Health 1989;1(4):470-84. 
11. Pugh MJ, Palmer RF, Parchman ML, Mortensen E, Markides K, Espino DV. Association of suboptimal prescribing and change in lower extremity physical function over time. Gerontology. 2007;53(6):445-53.

12. Rosso AL, Eaton CB, Wallace R, Gold R, Stefanick ML, Ockene JK et al. Geriatric syndromes and incident disability in older women: results from the women's health initiative observational study. J Am Geriatr Soc 2013;61(3):371-9.

13. Sganga F, Vetrano DL, Volpato S, Cherubini A, Ruggiero C, Corsonello A, et al. Physical performance measures and polypharmacy among hospitalized older adults: results from the CRIME study. J Nutr Health Aging 2014;18(6):616-21.

14. Vetrano DL, Villani ER, Grande G, Giovannini S, Cipriani MC, ManesGravina E, et al. Association of polypharmacy with 1-year trajectories of cognitive and physical function in nursing home residents: results from a multicenter European study. J Am Med Dir Assoc 2018;19(8):710-3.

15. Fabbietti P, Ruggiero C, Sganga F, Fusco S, Mammarella F, Barbini N, et al. Effects of hyperpolypharmacy and potentially inappropriate medications (PIMs) on functional decline in older patients discharged from acute care hospitals. Arch Gerontol Geriatr 2018;77:158-62.

16. Rawle MJ, Cooper R, Kuh D, Richards M. Associations between polypharmacy and cognitive and physical capability: a British birth cohort study. J Am Geriatr Soc 2018;66(5):916-23.

17. Crentsil V, Ricks MO, Xue QL, Fried LP. A pharmacoepidemiologic study of community-dwelling, disabled older women: Factors associated with medication use. Am J Geriatr Pharmacother 2010;8(3):215-24.

18. Dwyer LL, Han B, Woodwell DA, Rechtsteiner EA. Polypharmacy in nursing home residents in the United States: results of the 2004 National Nursing Home Survey. Am J Geriatr Pharmacother 2010;8(1):63-72.

19. George C, Verghese J. Polypharmacy and gait performance in community-dwelling older adults. J Am Geriatr Soc 2017;65(9):2082-7.

20. Gnjidic D, Hilmer SN, Blyth FM, Naganathan V, Waite L, Seibel MJ, et al. Polypharmacy cutoff and outcomes: five or more medicines were used to identify community-dwelling older men at risk of different adverse outcomes. J Clin Epidemiol 2012;65(9):989-95.

21. Junius-Walker U, Theile G, Hummers-Pradier E. Prevalence and predictors of polypharmacy among older primary care patients in Germany. Fam Pract 2007;24(1):14-9.

22. Kuzuya M, Masuda Y, Hirakawa Y, Iwata M, Enoki H, Hasegawa J, et al. Underuse of medications for chronic diseases in the oldest of communitydwelling older frail Japanese. J Am Geriatr Soc 2006;54(4):598-605.

23. Tsuji-Hayashi Y, Fukuhara S, Green J, Kurokawa K. Use of prescribed drugs among older people in Japan: association with not having a regular physician. J Am Geriatr Soc 1999;47(12): 1425-9.

24. Volaklis KA, Thorand B, Peters A, Halle M, Heier M, Strasser B, et al. Physical activity, muscular strength, and polypharmacy among older multimorbid persons: results from the KORA-Age study. Scand J Med Sci Sports 2018;28(2):604-12.

25. Kadam UT. Potential health impacts of multiple drug prescribing for older people: a case-control study. Br J Gen Pract 2011;61(583):128-30.

26. Campins L, Camps M, Riera A, Pleguezuelos E, Yebenes JC, SerraPrat M. Oral drugs related with muscle wasting and sarcopenia. A review. Pharmacology. 2017;99(1-2): 1-8.

27. Verbrugge LM, Jette AM. The disablement process. Soc Sci Med 1994;38(1): 1-14.

28. Ramkumar S, Raghunath A, Raghunath S. Statin therapy: review of safety and potential side effects. Acta Cardiologica Sinica 2016;32(6):631-9.

29. Ladage D, Schwinger RH, Brixius $\mathbf{K}$. Cardio-selective beta-blocker: pharmacological evidence and their influence on exercise capacity. Cardiovasc Ther 2013;31(2):76-83.

30. Barreto R, Mandili G, Witzmann FA, Novelli F, Zimmers TA, Bonetto A. Cancer and chemotherapy contribute to muscle loss by activating common signaling pathways. Front Physiol 2016;7:472-

31. Klein GL. The effect of glucocorticoids on bone and muscle. Osteoporos Sarcopenia 2015;1(1):39-45.

32. Kouladjian L, Gnjidic D, Chen TF, Mangoni AA, Hilmer SN. Drug Burden Index in older adults: theoretical and practical issues. Clin Interv Aging 2014;9: 1503-15.

33. Blair SN, Church TS. The importance of physical activity and cardiorespiratory fitness for patients with type 2 diabetes. Diabetes Spectr 2003; 16(4):236-40.

34. Horder H, Johansson L, Guo X, Grimby G, Kern S, Ostling S, et al. Midlife cardiovascular fitness and dementia: a 44-year longitudinal population study in women. Neurology. 2018;90(15):e1298-e305.

35. Kodama S, Saito $\mathbf{K}$, Tanaka S, Maki M, Yachi Y, Asumi M, et al. Cardiorespiratory fitness as a quantitative predictor of all-cause mortality and cardiovascular events in healthy men and women: a meta-analysis. JAMA. 2009;301(19):2024-35.

36. Kunutsor SK, Laukkanen T, Laukkanen JA. Cardiorespiratory fitness is associated with reduced risk of respiratory diseases in middle-aged caucasian men: a long-term prospective cohort study. Lung. 2017;195(5):607-11

37. Longenberger A, Lim JY, Brown TT, Abraham A, Palella FJ, Effros RB, et al. Low physical function as a risk factor for incident diabetes mellitus and insulin resistance. Futur Virol 2011;6(4):439-49.

38. Vainshelboim B, Muller J, Lima RM, Nead KT, Chester C, Chan K, et al. Cardiorespiratory fitness and cancer incidence in men. Ann Epidemiol 2017;27(7):442-7.

39. Naci H, Ioannidis JPA. Comparative effectiveness of exercise and drug interventions on mortality outcomes: metaepidemiological study. $\mathrm{Br}$ Sports Med 2013;347:15577.

40. Kokkinos P, Faselis C, Myers J, Kokkinos JP, Doumas M, Pittaras A, et al. Statin therapy, fitness, and mortality risk in middle-aged hypertensive male veterans. Am J Hypertens 2014;27(3):422-30.

41. Kokkinos P. Cardiorespiratory fitness, exercise, and blood pressure. Hypertension. 2014;64(6):1160-4.

42. Chimen M, Kennedy A, Nirantharakumar K, Pang TT, Andrews $\mathbf{R}$ Narendran P. What are the health benefits of physical activity in type 1 diabetes mellitus? A literature review. Diabetologia. 2012;55(3):542-51.

43. Vina J, Sanchis-Gomar F, Martinez-Bello V, Gomez-Cabrera MC Exercise acts as a drug; the pharmacological benefits of exercise. $\mathrm{Br} \mathrm{J}$ Pharmacol 2012;167(1):1-12.

44. Viña $\mathbf{J}$, Rodriguez-Mañas $\mathbf{L}$, Salvador-Pascual A, TarazonaSantabalbina FJ, Gomez-Cabrera MC. Exercise: the lifelong supplement for healthy ageing and slowing down the onset of frailty. J Physiol 2016;594(8): 1989-99.

45. Painter P, Stewart AL, Carey S. Physical functioning: definitions, measurement, and expectations. Adv Ren Replace Ther 1999;6(2):110-23.

46. Cantlay A, Glyn T, Barton N. Polypharmacy in the elderly. InnovAiT. 2016;9(2):69-77.

47. Piau A, Huet Y, Gallini A, Andre L, Vellas B, Nourhashemi F Optimization of drug therapy in elderly individuals admitted to a geriatric unit. Clin Interv Aging 2017;12:1691-6.

48. Gibert P, Cabaret M, Moulis M, Bosson J-L, Boivin J-E, Chanoine S, et al. Optimizing medication use in elderly people in primary care: Impact of STOPP criteria on inappropriate prescriptions. Arch Gerontol Geriatr 2018;75: 16-9.

49. Yorston LC, Kolt GS, Rosenkranz RR. Physical activity and physical function in older adults: the 45 and up study. J Am Geriatr Soc 2012;60(4):719-25.

50. Paterson DH, Warburton DE. Physical activity and functional limitations in older adults: a systematic review related to Canada's Physical Activity Guidelines. Int J Behav Nutr Phys Act 2010;7:38.

51. Simonsick EM, Guralnik JM, Volpato S, Balfour J, Fried LP. Just get out the door! Importance of walking outside the home for maintaining mobility: findings from the women's health and aging study. J Am Geriatr Soc 2005;53(2):198-203.

52. Hughes SL, Seymour RB, Campbell RT, Whitelaw N, Bazzarre T. Bestpractice physical activity programs for older adults: findings from the national impact study. Am J Public Health 2009;99(2):362-8.

53. Bayliss EA, Bayliss MS, Ware JE Jr, Steiner JF. Predicting declines in physical function in persons with multiple chronic medical conditions: what we can learn from the medical problem list. Health Qual Life Outcomes. 2004;2:47

54. Kadam UT, Croft PR, North Staffordshire GPCG. Clinical multimorbidity and physical function in older adults: a record and health status linkage study in general practice. Fam Pract 2007;24(5):412-9.

55. Loza E, Jover JA, Rodriguez L, Carmona L, Group ES. Multimorbidity: prevalence, effect on quality of life and daily functioning, and variation of this effect when one condition is a rheumatic disease. Semin Arthritis Rheum 2009;38(4):312-9.

56. Marengoni A, von Strauss E, Rizzuto D, Winblad B, Fratiglioni L. The impact of chronic multimorbidity and disability on functional decline and survival in elderly persons. A community-based, longitudinal study. J Intern Med 2009;265(2):288-95.

57. Althubaiti A. Information bias in health research: definition, pitfalls, and adjustment methods. J Multidiscip Healthe 2016;9:211-7.

Publisher's Note Springer Nature remains neutral with regard to jurisdictional claims in published maps and institutional affiliations. 